\title{
Relation of cervical length at 22-24 weeks of gestation to demographic characteristics and obstetric history
}

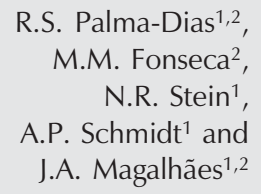

\author{
${ }^{1}$ Serviço de Obstetrícia e Ginecologia, Hospital de Clínicas de Porto Alegre, \\ Universidade Federal do Rio Grande do Sul, Porto Alegre, RS, Brasil \\ ${ }^{2}$ Clínica de Ultra-som Alpha, Porto Alegre, RS, Brasil
}

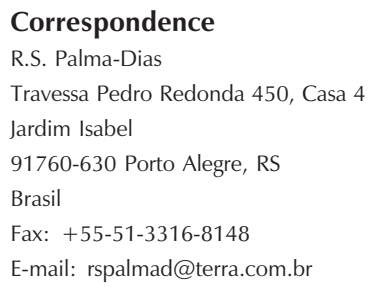

Received August 20, 2002 Accepted January 5, 2004 .....................

Abstract

Preterm delivery is the main cause of neonatal death and ultrasonographic cervical assessment has been shown to be more accurate than digital examination in recognizing a short cervix. This is a crosssectional study, involving 1131 women at 22-24 weeks of pregnancy, designed to determine the distribution of cervical length and to examine which variables of demographic characteristics and obstetric history increase the risk of a short cervix (15 mm or less). The distribution of maternal demographic and obstetric history characteristics among patients with cervical length $\leq 15 \mathrm{~mm}$ was analyzed and compared to the findings for the general population. Risk ratios (RR) between subgroups were generated from this comparison. Median cervical length was $37 \mathrm{~mm}$ and in $1.5 \%$ of cases it was $15 \mathrm{~mm}$ or less. The proportion of women with a short cervix $(\leq 15 \mathrm{~mm})$ was significantly higher among patients with a low body mass index $(R R=3.5)$ and in those with previous fetal losses between 16-23 weeks ( $R R=$ $33.1)$ or spontaneous preterm deliveries between 24-32 weeks $(\mathrm{RR}=$ 14.1). We suggest that transvaginal sonographic measurement of cervical length be performed as part of a routine midtrimester ultrasound evaluation. There are specific variables of demographic characteristics and obstetric history which increase the risk of detecting a short cervix at 22-24 weeks.
Key words

- Cervical length

- Preterm delivery screening

- Transvaginal sonography

- Perinatal medicine

\section{Introduction}

Preterm delivery is the main cause of neonatal death (1). The risk for this pregnancy complication varies with maternal characteristics, such as ethnic origin, age, body mass index (BMI), cigarette smoking and drug abuse, as well as obstetric history.

Routine assessment of cervical length at 22-24 weeks of gestation provides a sensi- tive prediction of spontaneous preterm delivery $(2,3)$. The likelihood of a spontaneous preterm delivery increases as the cervical length decreases. A study of 2567 pregnant women correlating cervical length at midtrimester and gestational age at delivery has shown that there is a significant increase in preterm delivery rate when cervical length is shorter than $15 \mathrm{~mm}$ (3). At 22-24 weeks, cervical length measurement can be carried 
out simultaneously with the fetal anomaly scan at a gestational age just prior to fetal viability. Furthermore, several studies have shown that ultrasonographic cervical assessment is more accurate than digital examination for identifying cervical changes $(4,5)$.

Transvaginal cervical length measurement has several technical advantages over the transabdominal approach. The main one is that a full bladder, often necessary to visualize the cervix transabdominally, may falsely elongate a short cervix due to the pressure exerted over the lower uterine segment (6).

The aims of the present study were to determine the distribution of cervical lengths in a population of singleton pregnancies at 22-24 weeks of gestation, and to examine the relationship between cervical length and maternal demographic characteristics and obstetric history. Furthermore, this study was planned to identify which variables of these characteristics increase the risk of detecting a cervical length of $15 \mathrm{~mm}$ or less, which is associated with a higher risk of spontaneous premature delivery.

\section{Patients and Methods}

All women attending the routine prenatal care service at Hospital de Clínicas de Porto Alegre, Porto Alegre, RS, Brazil, are offered the option of having two ultrasound examinations: the first at 11-14 weeks of gestation and the second at 22-24 weeks. During a 19month period (April 1999 to October 2000), women attending the midtrimester scan were offered the option of having transvaginal sonographic assessment of the cervix. Women with in situ cervical cerclage, severe fetal malformations or polyhydramnios were excluded from the study.

Written informed consent was obtained from women who agreed to participate in the study, which was approved by the hospital Ethics Committee and by the Brazilian National Ethics Committee. This study was part of a multicenter study carried out under the auspices of the Fetal Medicine Foundation, London, in order to find women with a short cervix and to test the effect of different treatment options for these high-risk patients.

The women were asked to empty their bladder and were placed in the dorsal lithotomy position. Transvaginal sonography with a 5-MHz transducer (Aloka1700 II SSD, Aloka Co. Ltd., Tokyo, Japan) was carried out by one of two sonographers who had received the Fetal Medicine Foundation Certificate of competence in cervical assessment. The probe was placed in the anterior fornix of the vagina and a sagittal view of the cervix, with the echogenic endocervical mucosa along the length of the canal, was obtained. Care was taken to avoid exerting undue pressure on the cervix. The electronic calipers were used to measure the distance between the triangular area of echodensity at the external os and the V-shaped notch at the internal os (Figure 1) (6). Each examination was performed during a period of about 3 min to observe any cervical changes. Changes that may be due to contractions are observed in less than $1 \%$ of patients and, in such cases, the shortest measurement is recorded. The presence or absence of funneling at the internal os was recorded (Figure 2).

The following data were obtained in a structured interview at the time when consent for the study was obtained: ethnic group, age, weight and height for the calculation of BMI, smoking status, and history of previous cervical surgery. Obstetric history including all previous topic pregnancies was obtained and organized as follows: 1) primigravidae; 2) non-primigravidae, subdivided into: a) births $>37$ weeks, b) births between 33 and 36 weeks, c) births between 24 and 32 weeks, d) fetal loss between 16 and 23 weeks, e) termination of pregnancy before 16 weeks, f) miscarriage before 16 weeks, and g) termination of pregnancy before 16 weeks. These data were entered in a computer database together with the ultrasound scan results. 
Gestational age was determined from the menstrual history and confirmed from the first-trimester scan. When the difference between the two estimates was more than seven days the ultrasound result was used for dating.

The distribution of cervical lengths was tested for normality using the KolmogorovSmirnov test. The Tukey-HSD test for multiple range comparisons and the unpaired Student $t$-test were used to calculate the significance of differences in mean cervical length between subgroups. The chi-square test and the Fisher exact test were used to determine the significance of differences between subgroups in cases with cervical length $\leq 15 \mathrm{~mm}$ (Table 4); this cut-off identifies a group at higher risk for preterm delivery (3). A 5\% alpha error was admitted (P < $0.05)$.

For analysis of obstetric history, patients were divided into subgroups. Patients with unfavorable obstetric history (miscarriages, spontaneous preterm deliveries) were compared to a control group of women with a history of exclusively term deliveries (Table 5). Patients in their first pregnancy were analyzed separately.

\section{Results}

During the study period, 1157 women with singleton pregnancies were seen for a scan at 22-24 (median $=23)$ weeks of gestation and $1131(97.8 \%)$ agreed to participate in the study.

Cervical length was measured successfully in all cases. Length was approximately distributed normally with some skewness at the lower end (Figure 3). The median (and mean) value was $37 \mathrm{~mm}$, and the $1 \mathrm{st}$ and 5th percentiles were 13 and $25 \mathrm{~mm}$, respectively. In $11.8,5.0,2.4$ and $1.5 \%$ of cases, the cervical length was $\leq 30, \leq 25, \leq 20$ and $\leq 15 \mathrm{~mm}$, respectively (Table 1).

Funneling of the cervical canal at the level of the internal os was observed in 20

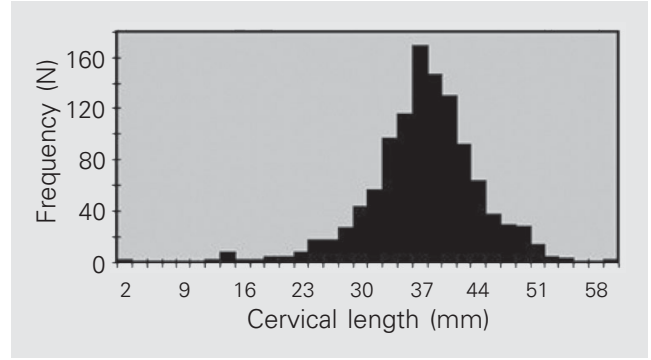

Figure 1. Cervical length-frequency distribution. $\mathrm{N}=1131$.

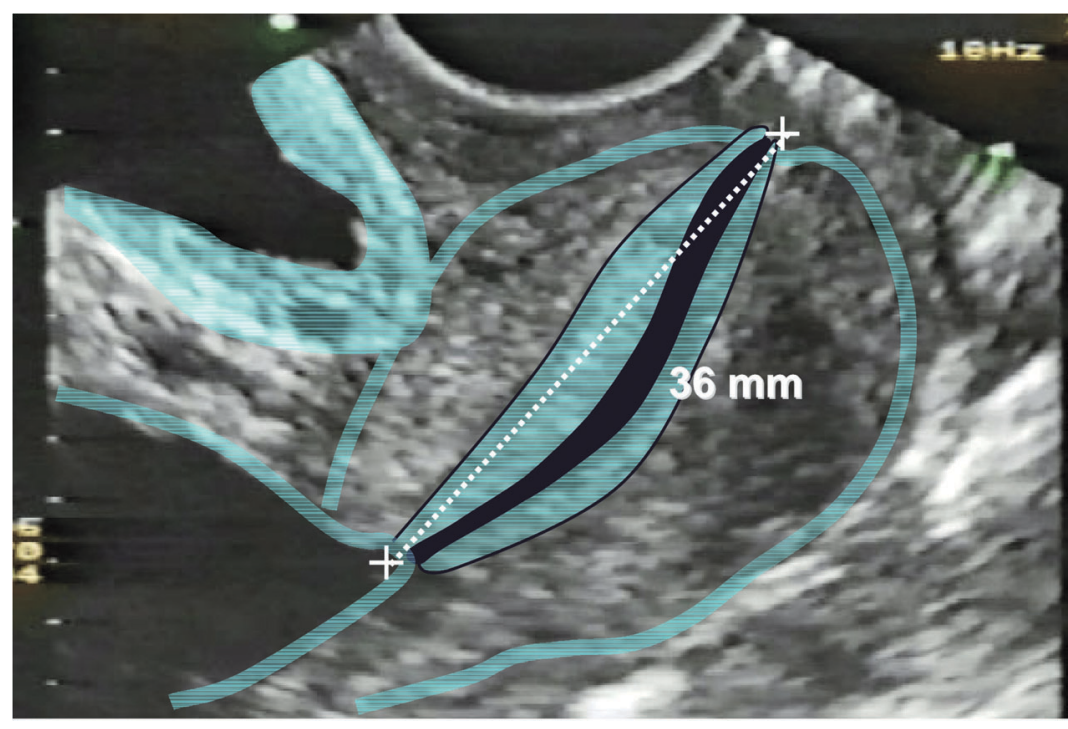

Figure 2. Normal $(36 \mathrm{~mm})$ cervical length measurement.

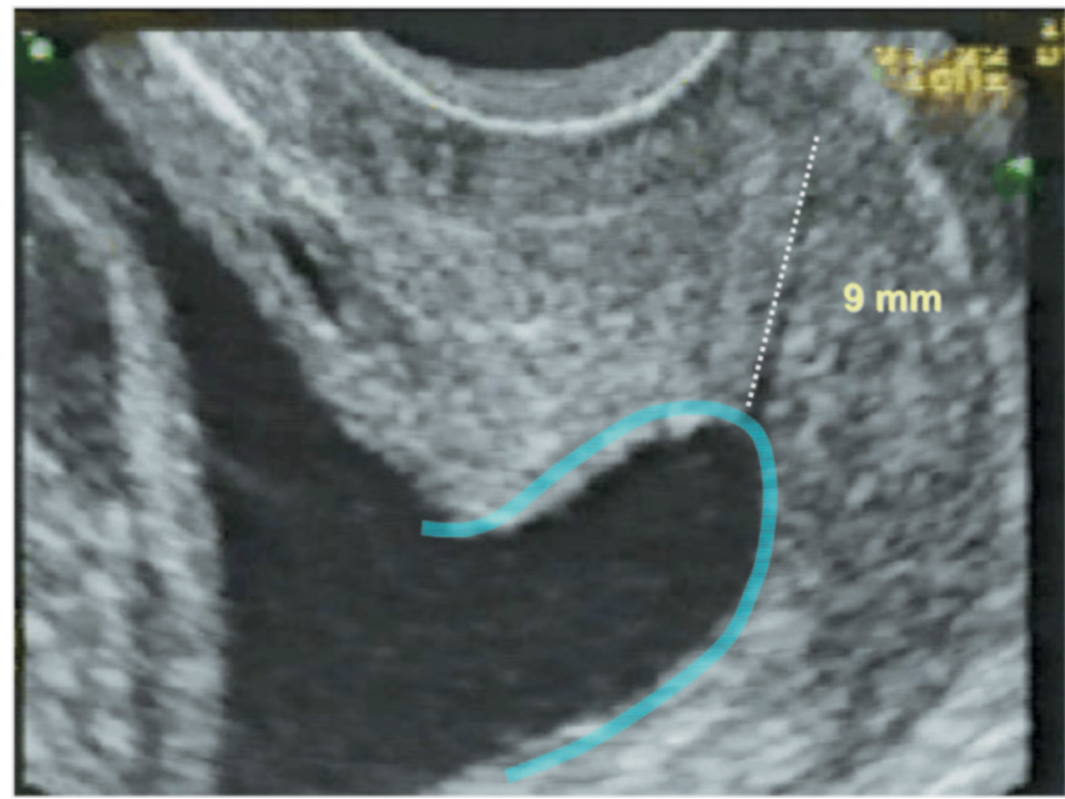

Figure 3. Short cervix (9 mm) with funneling. 
$(1.8 \%)$ cases and in $76.5 \%$ of the cases with cervical length $\leq 15 \mathrm{~mm}$.

The mean cervical length was shorter in women aged less than 20 years and in those with an unfavorable obstetric history (Tables 2 and 3). In terms of obstetric history, $35 \%$ of the patients had no previous pregnancies, $25 \%$ had one or more miscarriages and/or termination of pregnancy before 16 weeks of gesta-

Table 1. Incidence of short cervixes when different cervical lengths are used as cut-offs.

\begin{tabular}{lc}
\hline Cervical length $(\mathrm{mm})$ & Incidence (\%) \\
\hline$\leq 15 \mathrm{~mm}$ & 1.5 \\
$\leq 20 \mathrm{~mm}$ & 2.4 \\
$\leq 25 \mathrm{~mm}$ & 5.0 \\
$\leq 30 \mathrm{~mm}$ & 11.8
\end{tabular}

$\mathrm{N}=1124$. Mean and median cervical length $=37$ $\mathrm{mm}$; $1 \mathrm{st}$ percentile $=13 \mathrm{~mm}$; 5 th percentile $=25$ $\mathrm{mm}$.

Table 2. Cervical length at 22-24 weeks of gestation: patient characteristics and comparison of means for each subgroup.

\begin{tabular}{|c|c|c|c|c|}
\hline Characteristics & N (\%) & $\begin{array}{c}\text { Cervical } \\
\text { length }(\mathrm{mm})\end{array}$ & $\begin{array}{l}\text { Group } \\
\text { comparison }\end{array}$ & $\begin{array}{c}\text { Mean } \\
\text { difference }(95 \% \mathrm{Cl})\end{array}$ \\
\hline \multicolumn{5}{|l|}{ Ethnic group } \\
\hline Caucasian $^{1}$ & 892 (78.9) & $36.9(6.8)$ & $1 \times 2$ & $1.16(-0.10$ to 2.42$)$ \\
\hline African ${ }^{2}$ & $131(11.6)$ & $35.7(7.4)$ & $2 \times 3$ & $-1.03(-2.79$ to 0.78$)$ \\
\hline Mixed $^{3}$ & 108 (9.5) & $36.7(6.4)$ & $1 \times 3$ & $0.16(-1.19$ to 1.51$)$ \\
\hline \multicolumn{5}{|l|}{ Age (years) } \\
\hline$<20^{1}$ & $170(15.0)$ & $34.2(7.4)^{*}$ & $1 \times 2$ & $-2.80(-3.93$ to -1.68$)$ \\
\hline $20-35^{2}$ & $759(67.1)$ & $37.1(6.6)$ & $2 \times 3$ & $-0.34(-1.38$ to 0.69$)$ \\
\hline$>35^{3}$ & 202 (17.9) & $37.3(6.8)^{*}$ & $1 \times 3$ & $-3.15(-4.60$ to -1.69$)$ \\
\hline \multicolumn{5}{|l|}{ Body mass index } \\
\hline$<19.8^{1}$ & $65(5.7)$ & $34.5(7.2)$ & $1 \times 2$ & $-1.50(-3.29$ to 0.29$)$ \\
\hline $19.8-26^{2}$ & 677 (59.9) & $36.0(7.0)^{*}$ & $2 \times 3$ & $-2.27(-3.08$ to -1.46$)$ \\
\hline$>26^{3}$ & 389 (34.4) & $38.2(6.2)^{*}$ & $1 \times 3$ & $-3.77(-5.65$ to -1.88$)$ \\
\hline \multicolumn{5}{|l|}{ Smoking } \\
\hline Smokers ${ }^{1}$ & $168(14.9)$ & $36.9(6.9)$ & $1 \times 2$ & $0.21(-0.92$ to 1.33$)$ \\
\hline Non-smokers ${ }^{2}$ & $963(85.1)$ & $36.7(6.8)$ & & \\
\hline \multicolumn{5}{|l|}{ Cervical surgery } \\
\hline Cone biopsy ${ }^{1}$ & $8(0.7)$ & $35.3(23.4)$ & $1 \times 3$ & $-1.41(-6.18$ to 3.36$)$ \\
\hline Other ${ }^{2}$ & $57(5.1)$ & $36.4(6.6)$ & $2 \times 3$ & $-0.28(-2.11$ to 1.54$)$ \\
\hline None $^{3}$ & 1066 (94.3) & $36.7(6.9)$ & $1+2 \times 3$ & $-0.43(-2.14$ to 1.28$)$ \\
\hline
\end{tabular}

Cervical length is reported as mean and $\mathrm{SD}$ in $\mathrm{mm}$ for $\mathrm{N}=1131$. ${ }^{*} \mathrm{P} \leq 0.05$ (see group comparison; Tukey test for multiple ranges). The smoking and non-smoking groups were compared by the Student $t$-test. $\mathrm{Cl}=$ confidence interval. tion, $46 \%$ had one or more term deliveries, with or without previous fetal losses before 16 weeks, $9 \%$ had at least one previous spontaneous preterm delivery at $33-36$ weeks, $4 \%$ had at least one previous spontaneous preterm delivery at 24-32 weeks, 5\% had at least one previous miscarriage at 16-23 weeks, and $1 \%$ had at least one previous termination at 16-23 weeks. Some patients in the latter four groups may also have had first-trimester losses or term deliveries. The groups are compared for mean cervical length in Table 3.

Women with increased BMI $(>26)$ had increased mean cervical length compared to those with normal or decreased BMI.

In women of African origin the mean cervical length tended to be shorter compared to Caucasians, but the difference was not statistically significant. The mean cervical length was not significantly different when women were compared for the use of cigarettes or for past cervical surgery (Table 2).

The proportion of women with a very short cervix $(\leq 15 \mathrm{~mm})$ was significantly increased in women with a low BMI and in those with previous miscarriages or spontaneous preterm deliveries (Tables 4 and 5).

Non-Caucasians, patients aged 20 years or less, smokers, those who underwent cervical conization and those with first trimester losses were present in a higher than expected proportion in the short cervix $(\leq 15$ $\mathrm{mm}$ ) group. However, the difference between their expected and observed frequency was not statistically significant in these subgroups (Tables 4 and 5).

\section{Discussion}

The present study has demonstrated that the mean cervical length of $37 \mathrm{~mm}$ was similar to that of other studies that measured cervical length at 20-24 weeks in low-risk populations in different settings (Table 6) (2,7-19).

The incidence of preterm delivery is higher in all ethnic minorities, particularly in 
those of African origin, but two large American studies have reported that, when social and demographic factors were accounted for, maternal race was not a significant risk factor for preterm delivery $(20,21)$. In our study, women of African origin did not show a significantly shorter cervical length than Caucasian women. This finding, which disagrees with other studies with a similar design, may be explained by the high rate of ethnic group mixing found in the Brazilian population, where ethnic group differences may become subtle. Furthermore, all our patients, regardless of ethnic origin, come from lower social classes. This may explain our findings, agreeing with the observation that social and economic status might be more important than ethnic group itself in predicting a poorer pregnancy outcome.

We found that cervical length was shorter in women aged less than 20 years. This is compatible with the well-documented increased risk for poorer pregnancy outcome in adolescents. It has been previously suggested that this increased risk is probably due to associated social and behavioral factors rather than to intrinsic biological determinants of young age (22). This is an important finding for our population, given the high incidence of adolescents who conceive in Brazil, suggesting that this age group would benefit particularly from cervical assessment as a screening tool for preterm delivery.

The incidence of preterm delivery is higher in women that smoke than in nonsmokers $(23,24)$. It has been suggested that smoking may induce labor by increasing the amniotic fluid concentration of the inflammatory mediator platelet-activating factor since cigarette smoke is a potent inhibitor of the enzyme that degrades platelet-activating factor (25). We found that mean cervical length in cigarette smokers was not significantly lower than in non-smokers. However, women who smoked were more likely to be part of the very short cervix group $(\leq 15 \mathrm{~mm})$. These findings are in agreement with our understanding of how preterm labor is triggered: both mechanical and biochemical factors might play a role in this process through different mechanisms of action.

The incidence of preterm delivery may

Table 3. Cervical length at 22-24 weeks of gestation: obstetric history and comparison of means for each subgroup.

\begin{tabular}{|c|c|c|c|c|}
\hline Obstetric history & N (\%) & $\begin{array}{c}\text { Cervical } \\
\text { length } \\
(\mathrm{mm})\end{array}$ & $\begin{array}{l}\text { Statistical } \\
\text { comparison }\end{array}$ & $\begin{array}{c}\text { Mean } \\
\text { difference } \\
(95 \% \mathrm{Cl})\end{array}$ \\
\hline Primigravidae ${ }^{1}$ & $398(35.2)$ & $35.5(6.9)$ & $1 \times 2$ & $-1.89(-2.35$ to 1.66$)$ \\
\hline Multigravidae ${ }^{2}$ & $733(64.8)$ & $37.4(6.7)$ & & \\
\hline Delivery $\geq 37$ weeks $A$ & 309 (27.3) & $38.7(6.1)$ & & \\
\hline Delivery 33-36 weeks ${ }^{B}$ & $96(8.5)$ & $36.4(7.5)^{*}$ & $A \times B$ & $-2.4(-4.0$ to -0.7$)$ \\
\hline Delivery 24-32 weeks C & $44(3.9)$ & $34.7(8.9)^{*}$ & $A \times C$ & $-4.1(-6.9$ to -1.3$)$ \\
\hline Fetal loss $16-23$ weeks ${ }^{D}$ & $56(5.0)$ & $34.5(9.2)^{*}$ & $A \times D$ & $-4.3(-6.8$ to -1.7$)$ \\
\hline Termination $16-23$ weeks $\mathrm{E}$ & $9(0.8)$ & $35.5(6.5)$ & $A \times E$ & $-3.3(-8.3$ to +1.8$)$ \\
\hline Fetal loss $<16$ weeks $F$ & $239(21.1)$ & $35.7(7.1)^{*}$ & $A \times F$ & $-3.1(-4.2$ to -1.9$)$ \\
\hline Termination $<16$ weeks ${ }^{G}$ & $41(3.6)$ & $38.5(7.6)$ & $A \times G$ & $-0.3(-2.3$ to +1.8$)$ \\
\hline
\end{tabular}

Cervical length is reported as mean and $\mathrm{SD}$ in $\mathrm{mm}$ for $\mathrm{N}=1131 . \mathrm{Cl}=$ confidence interval.

${ }^{*} \mathrm{P}<0.05$ compared to group A (Student $t$-test).

Table 4. Incidence of cervical length of $15 \mathrm{~mm}$ or less in each subgroup.

\begin{tabular}{|c|c|c|c|c|}
\hline & $\mathrm{N}$ & $\begin{array}{c}\text { Cervix }<15 \mathrm{~mm} \\
\mathrm{~N}(\%)\end{array}$ & $\mathrm{RR}(95 \% \mathrm{Cl})$ & $\begin{array}{l}\text { Statistical } \\
\text { comparison }\end{array}$ \\
\hline \multicolumn{5}{|l|}{ Ethnic group } \\
\hline Caucasian ${ }^{1}$ & 892 & $13(1.5)$ & $1.15(0.38-3.49)$ & $1 \times 2$ \\
\hline Non-Caucasian ${ }^{2}$ & 239 & $4(3.1)$ & & \\
\hline \multicolumn{5}{|l|}{ Age (years) } \\
\hline$<20^{1}$ & 170 & $5(2.9)$ & $2.34(0.83-6.55)$ & $1 \times 2$ \\
\hline$\geq 20^{2}$ & 961 & $12(1.2)$ & & \\
\hline \multicolumn{5}{|l|}{ Body mass index } \\
\hline$<19.8^{1}$ & 65 & $3(4.6)^{*}$ & 3.51 (1.03-11.90) & $1 \times 2$ \\
\hline$\geq 19.8^{2}$ & 1066 & $14(1.3)$ & & \\
\hline \multicolumn{5}{|l|}{ Smoking } \\
\hline Smokers ${ }^{1}$ & 168 & $3(1.8)$ & $1.23(0.36-4.23)$ & $1 \times 2$ \\
\hline Non-smokers ${ }^{2}$ & 963 & $14(1.5)$ & & \\
\hline \multicolumn{5}{|l|}{ Cervical surgery } \\
\hline Cone biopsy ${ }^{1}$ & 8 & $1(1.8)$ & $1.18(0.62-3.23)$ & $1 \times 3$ \\
\hline Other ${ }^{2}$ & 57 & $0(0)$ & & \\
\hline None $^{3}$ & 1066 & $16(1.5)$ & & \\
\hline
\end{tabular}


be slightly higher in primiparous than in multiparous women (26,27). Our data showed a significant difference in cervical length between primiparous and multiparous women (Table 2). Once adolescent patients have been excluded from the sample, this difference no longer persists, which is in

Table 5. Incidence of cervical length of $15 \mathrm{~mm}$ or less in the obstetric history subgroups.

\begin{tabular}{|c|c|c|c|c|}
\hline Obstetric history & $\mathrm{N}$ & $\begin{array}{c}\text { Cervix }<15 \mathrm{~mm} \\
\quad \mathrm{~N}(\%)\end{array}$ & $\mathrm{RR}(95 \% \mathrm{Cl})$ & $\begin{array}{l}\text { Statistical } \\
\text { comparison }\end{array}$ \\
\hline Primigravidae ${ }^{1}$ & 398 & $8(2.0)$ & $1.64(0.63-4.21)$ & $1 \times 2$ \\
\hline Multigravidae ${ }^{2}$ & 733 & $9(1.2)$ & & \\
\hline $\begin{array}{l}\text { Delivery }>37 \text { weeks }{ }^{A} \\
\text { (control group) }\end{array}$ & 309 & $1(0.3)$ & & \\
\hline Delivery 33-36 weeks ${ }^{B}$ & 96 & $3(3.1)^{*}$ & 9.66 (1.02-91.76) & $A \times B$ \\
\hline Delivery 24-32 weeks C & 44 & $2(4.5)^{*}$ & $14.05(1.30-151.70)$ & $A \times C$ \\
\hline Fetal loss $16-23$ weeks ${ }^{D}$ & 56 & $6(10.7)^{*}$ & $33.10(4.06-269.76)$ & $A \times D$ \\
\hline Termination16-23 weeks $\mathrm{E}$ & 9 & $0(0)$ & $1.00(0.99-1.01)$ & $A \times E$ \\
\hline Fetal loss $<16$ weeks $F$ & 239 & $5(2.1)$ & $6.46(0.76-54.97)$ & $A \times F$ \\
\hline Termination $<16$ weeks $^{G}$ & 41 & $1(2.4)$ & $7.54(0.48-118.20)$ & $A \times G$ \\
\hline
\end{tabular}

The relative risk was calculated as a fraction of the percentage of women with a cervix $<15 \mathrm{~mm}$ in the overall population (1.5\%). $\mathrm{N}=1131 . \mathrm{Cl}=$ confidence interval; $\mathrm{RR}=$ risk ratio.

${ }^{*} \mathrm{P}<0.05$ compared to subgroup $A$ (chi-square test/Fisher's exact test).

Table 6. Studies of low-risk populations providing sufficient data to allow calculation of median or mean cervical length at 20-24 weeks of gestation.

\begin{tabular}{lcccc}
\hline Reference & Ultrasonography & N & $\begin{array}{c}\text { Cervical } \\
\text { length (mm) }\end{array}$ & $\begin{array}{c}\text { Primigravid } \\
\text { vs } \\
\text { multigravida }\end{array}$ \\
\hline Ayers et al., 1988 (8) & TA & 24 & 52 & Similar \\
Podobnik et al., 1988 (9) & TA & 80 & 48 & - \\
Andersen et al., 1990 (7) & TV & 19 & 40 & - \\
Kushnir et al., 1990 (10) & TA & 21 & 43 & - \\
Andersen, 1991 (11) & TV & 24 & 48 & Similar \\
& TV & 25 & 41 & MG > P \\
Murakawa et al., 1993 (12) & TA & 25 & 42 & - \\
Zorzoli et al., 1994 (13) & TV & 44 & 37 & Similar \\
lams et al., 1995 (14) & TV & 121 & 42 & MG > P \\
lams et al., 1996 (2) & TV & 106 & 37 & - \\
Cook and Ellwood, 1996 (15) & TV & 2915 & 35 & MG > P \\
Hasegawa et al., 1996 (16) & TV & 41 & 42 & P > MG \\
Tongsong et al., 1997 (17) & TV & 78 & 38 & Similar \\
Heath et al., 1998 (18) & TV & 38 & 42 & Similar \\
Carvalho et al., 2002 (19) & TV & 2702 & 38 & Similar \\
Palma Dias et al. (present study) & TV & 641 & 39 & - \\
& TV & 1131 & 37 & Similar \\
\hline TA = transabdominal; TV = transvaginal. ${ }^{2}$ Cervical length of & primigravid (P) women \\
compared to that of multigravid (MG) women. & & & \\
& & & &
\end{tabular}

accordance with most previous studies reporting on cervical length at midtrimester.

In terms of obstetric history, cervical length was shorter in patients with previous midtrimester losses or previous spontaneous preterm deliveries. Indeed, these findings corroborate classic principles of obstetrics which state that obstetric history is one of the best screening tools for identifying high-risk pregnancies.

However, not all patients with a poor obstetric history will prove to have abnormal cervical findings or a repeated unfavorable pregnancy outcome. Nevertheless, routine cervical assessment at 23 weeks in these patients may be reassuring to patients and obstetricians after a normal result, whereas the confirmation of anatomical changes compatible with cervical incompetence might justify the early institution of therapeutic strategies based on objective criteria.

Our findings do not corroborate the assumption that women with previous cervical surgery, especially cone biopsies, should have a shorter cervix. However, there are several studies showing an increase in preterm delivery after this type of surgery $(26,28,29)$. Although a significant difference in cervical length has not been found in women who underwent a cone biopsy, it is interesting to notice that the dispersion of this statistic is wide, since a part of these patients has indeed shown a cervical length more than 2 standard-deviations below the mean.

The possibility that this statistical finding reflects the existence of two different subgroups in the "cone biopsy" category must be considered. Cone biopsies directed to the ectocervix have a wider diameter and decreased depth compared to those directed to endocervical lesions, which implicate in deeper resections and therefore are more prone to cause cervical incompetence. The number of patients who underwent cervical assessment after a cone biopsy in our sample was small and, therefore, the above mentioned potential confounders could not be 
controlled in our study. Furthermore, most women who undergo a cone biopsy at our hospital are advised to have a first trimester cerclage in future pregnancies, and the presence of a cervical cerclage in situ at 23 weeks was a reason for exclusion from this study.

Low pre-pregnancy maternal weight is associated with an increased risk of preterm delivery, particularly in women who are markedly underweight (less than $80 \%$ of recommended weight for height) and have a low weight gain during pregnancy $(30,31)$. In our study, the median cervical length was longer in women with a high BMI and the incidence of a very short cervix $(<15 \mathrm{~mm})$ was higher in women with a low BMI $(<19.8)$.
There is evidence that short cervical length at 22-24 weeks of gestation is associated with increased risk of preterm delivery $(2,3)$. The present study has demonstrated that significant contributions to the explanation of the variance in cervical length are provided by ethnic group, BMI, maternal age and obstetric history.

Furthermore, the most important new results presented here are the significantly positive relationship between previous fetal losses between 16-23 weeks and previous preterm delivery between 24-32 weeks with the finding of a short cervix in an asymptomatic patient.

\section{References}

1. Guyer B, Martin JA, MacDorman MF, Anderson RN \& Strobino DM (1997). Annual summary of vital statistics - 1996. Pediatrics, 100: 905-918.

2. lams JD, Goldenberg RL, Meis PJ et al. (1996). The length of the cervix and the risk of spontaneous delivery. New England Journal of Medicine, 334: 567-572.

3. Heath VCF, Southall TR, Souka AP, Elisseou A \& Nicolaides KH (1998). Cervical length at 23 weeks of gestation: prediction of spontaneous preterm delivery. Ultrasound in Obstetrics and Gynecology, 12: 312-317.

4. Lim BH, Mahmood TA, Smith NC \& Beat I (1992). A prospective comparative study of transvaginal ultrasonography and digital examination of cervical assessment in the third trimester of pregnancy. Journal of Clinical Ultrasound, 20: 599-603.

5. Jackson GM, Ludmir J \& Bader TJ (1992). The accuracy of digital examination and ultrasound in the evaluation of cervical length. Obstetrics and Gynecology, 79: 214-218.

6. To MS, Skentou C, Cicero S \& Nicolaides KH (2000). Cervical assessment at the routine 23-week scan: problems with transabdominal sonography. Ultrasound in Obstetrics and Gynecology, 15: 292296.

7. Andersen HF, Nugent CE, Wanty SD \& Hayashi RH (1990). Prediction of risk for preterm delivery by ultrasonographic measurement of cervical length. American Journal of Obstetrics and Gynecology, 163: 859-867.

8. Ayers JW, DeGrood RM, Compton AA, Barclay M \& Ansbacher R (1988). Sonographic evaluation of cervical length in pregnancy: diagnosis and management of preterm cervical effacement in patients at high risk for premature delivery. Obstetrics and Gynecology, 71: 939-944

9. Podobnik M, Bulie M, Smiljjanie N \& Bistricki J (1988). Ultrasonography in the detection of cervical incompetency. Journal of Clinical Ultrasound, 13: 383-391.

10. Kushnir O, Vigil DA, Izquierdo L, Schiff M \& Curet LB (1990). Vaginal ultrasonographic assessment of cervical length changes during nor- mal pregnancy. American Journal of Obstetrics and Gynecology, 162: $991-993$

11. Andersen HF (1991). Transvaginal and transabdominal ultrasonography of the uterine cervix during pregnancy. Journal of Clinical Ultrasound, 19: 77-83.

12. Murakawa H, Utumi T, Hasegawa I, Tanaka K \& Fuzimori R (1993). Evaluation of threatened preterm delivery by transvaginal ultrasonographic measurement of cervical length. Obstetrics and Gynecology, 82: 829-832.

13. Zorzoli A, Soliani A, Perra M, Caravelli E, Galimberi A \& Nicolini U (1994). Cervical changes throughout pregnancy as assessed by transvaginal sonography. Obstetrics and Gynecology, 84: 960-964.

14. lams JD, Johnson FF, Sonek J, Sachs L, Gebauer C \& Samuels P (1995). Cervical competence as a continuum: a study of ultrasonographic cervical length and obstetrical performance. American Journal of Obstetrics and Gynecology, 172: 1097-1106.

15. Cook C-M \& Ellwood DA (1996). A longitudinal study of the cervix in pregnancy using transvaginal ultrasound. British Journal of Obstetrics and Gynecology, 103: 16-18.

16. Hasegawa I, Tanaka K, Takahashi K et al. (1996). Transvaginal ultrasonographic cervical assessment for the prediction of preterm delivery. Journal of Maternal and Fetal Medicine, 5: 305-309.

17. Tongsong T, Kamprapanth P \& Pitaksakorn J (1997). Cervical length in normal pregnancy as measured by transvaginal sonography. International Journal of Gynecology and Obstetrics, 58: 313-315.

18. Heath VCF, Southall TR, Souka AP, Novakov A \& Nicolaides KH (1998). Cervical length at 23 weeks of gestation: relation to demographic characteristics and previous obstetric hystory. Ultrasound in Obstetrics and Gynecology, 12: 304-311.

19. Carvalho MHB, Bittar RE, Gonzales M, Brizot ML \& Zugaib $M$ (2002). Avaliação do risco para parto prematuro espontâneo pelo comprimento do colo uterino no primeiro e segundo trimestre de gravidez. Revista Brasileira de Ginecologia e Obstetrícia, 24: 463468.

20. Lieberman E, Ryan KJ, Monson RR \& Schoenbaym SC (1987). Risk 
factors accounting for racial differences in the rate of premature birth. New England Journal of Medicine, 317: 743-748.

21. Owen J, Goldenberg RL, Davi RO, Kirk KA \& Copper RL (1990). Evaluation of a risk scoring system as a predictor of preterm birth in an indigent population. American Journal of Obstetrics and Gynecology, 163: 873-879.

22. Zuckerman BS, Walker DK, Frank DA, Chase C \& Hamburg B (1984). Adolescent pregnancy: biobehavioural determinants of outcome. Journal of Pediatrics, 105: 857-862.

23. Wen SW, Goldenberg RL, Cutter GR, Hoffman HJ \& Cliver SP (1990). Intrauterine growth retardation and preterm delivery: prenatal risk factors in an indigent population. American Journal of $\mathrm{Ob}$ stetrics and Gynecology, 162: 213-218.

24. Wisborg K, Henriksen TB, Hedegaard M \& Secher NJ (1996). Smoking during pregnancy and preterm birth. British Journal of Obstetrics and Gynecology, 103: 800-805.

25. Narahara H \& Johnston JM (1993). Smoking and preterm labor: effect of cigarette smoke extract on the secretion of platelet activating factor acetylhydrolase by human decidual macrophages.
American Journal of Obstetrics and Gynecology, 169: 1321-1326.

26. Heffner LJ, Sherman CB, Speizer FE \& Weiss ST (1993). Clinical and environmental predictors of preterm labor. Obstetrics and Gynecology, 81: 750-757

27. Kaltreider DF \& Kohl S (1980). Epidemiology of preterm delivery. Clinical Obstetrics and Gynecology, 23: 17-32.

28. Kristensen J, Langhoff-Roos J \& Kristensen FB (1993). Increased risk of preterm birth in women with cervical conisation. Obstetrics and Gynecology, 81: 1005-1008.

29. Hagen B \& Skjeldestad FE (1993). The outcome of pregnancy after $\mathrm{CO}_{2}$ laser conisation of the cervix. British Journal of Obstetrics and Gynecology, 100: 717-720.

30. Mitchell MC \& Lerner E (1989). Weight gain and pregnancy outcome in underweight and normal weight women. Journal of the American Dietetic Association, 89: 634-638.

31. Hickey CA, Cliver SP, McNeal SF \& Goldenberg RL (1997). Low pregravid body mass index as a risk factor for preterm birth: variation by ethnic group. Obstetrics and Gynecology, 82: 206-212. 